\title{
PROCEDÊNCIA DE PACIENTES COM LEISHMANIOSE DE MUCOSA EM ÁREA ENDÊMICA DA BAHIA, BRASIL
}

Existe na literatura relatos de ligação de prevalência de leishmaniose cutânea com a derrubada de florestas 6 7: estudamos neste relato a origem de leishmaniose mucosa e sua inter-relação com a presença de florestas.
Trabalhamos há 9 anos no norte da região cacaueira da $\mathrm{Bahia}^{2}$, dentro do polígono que compreende: Três Braços-1, Corte de Pedra-2, Jiquiriçá-3, Itamari-4, Teolândia-A, Santa Inês-B, e CravolândiaC (Ver Mapa). Os dois primeiros locais são

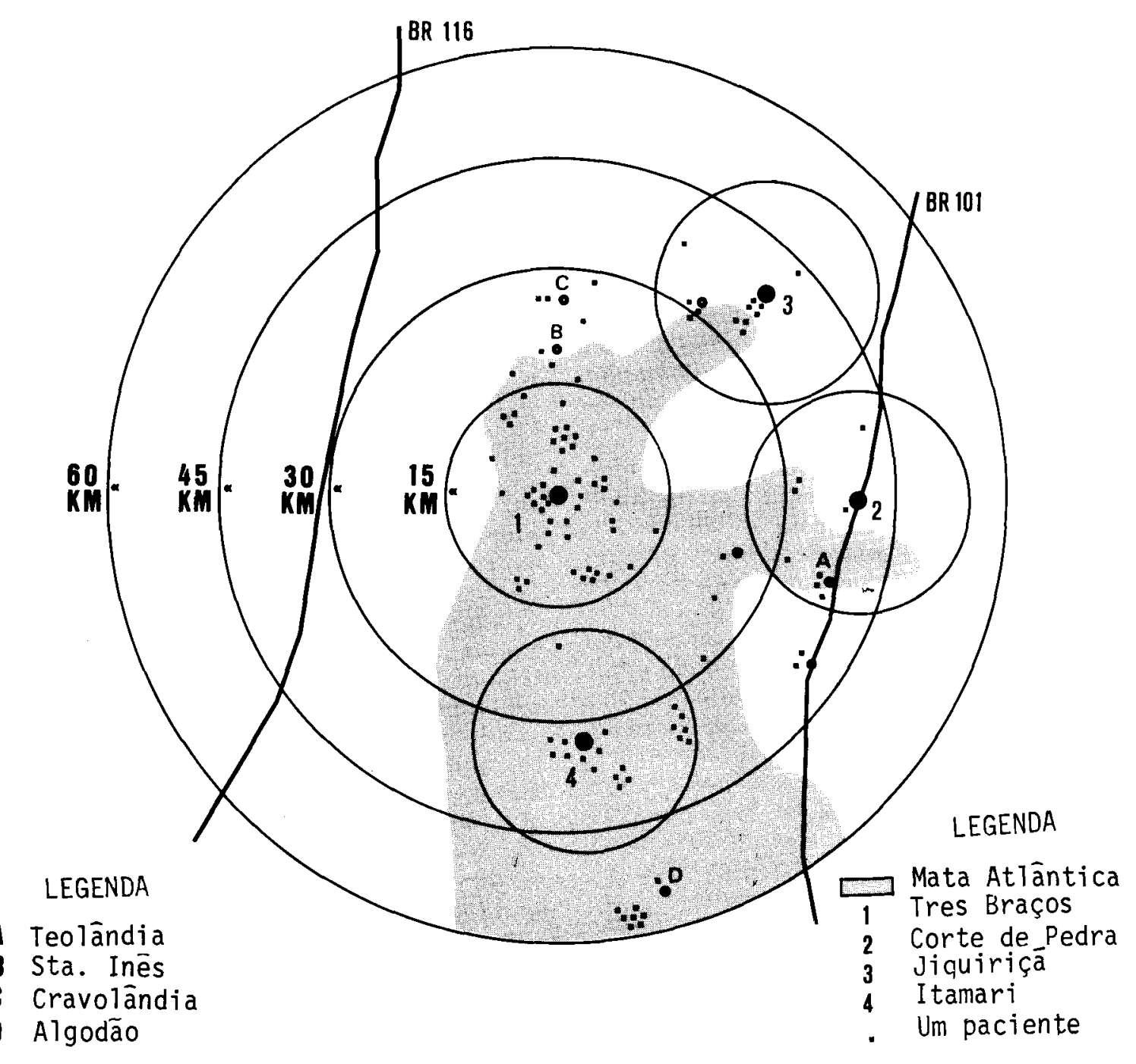

Mapa mostrando a relação da mata atlântica residual com a distribuição geográfica de pacientes com leishmaniose de mucosa. 
distritos onde instalamos Postos Clínicos, enquanto as demais localidades são cidades que apresentam infra-estrutura básica de saúde, ambas, vivendo em função da lavoura do cacau ${ }^{1}$.

Atualmente, ultrapassamos o numero de 1000 pacientes com leishmaniose tegumentar atendidos nesses postos. Notamos um predominio absoluto da Leishmania braziliensis braziliensis, ${ }^{2} 97 \%$ dos isolados foram classificados como pertencentes a esta espécie ${ }^{3}$.

Os casos de acometimento mucoso até janeiro de 1983 somavam um total de 100 pacientes $(10 \%$ da casuistica geral) dos quais $48 \%$ residiam em um raio de $15 \mathrm{~km}$ do Posto de Três Braços, onde iniciamos o nosso trabalho. Infelizmente não se pôde chegar à conclusão que tais $10 \%$ significam a prevalência atual da forma mucosa, por causa do vicio da amostra.

Há 4 anos estendemos o atendimento às localidades de Itamari e Jiquiriçá e, há 3 anos, à Corte de Pedra, onde fomos surpreendidos por um surto epidêmico de leishmaniose (JML Costa: comunicação pessoal). Oitenta e oito pacientes ( $88 \%$ ) residem em um raio de $15 \mathrm{~km}$ de algum destes Postos (Ver Mapa).

Segundo a nossa ficha clinica, todos os pacientes residem em um raio de $45 \mathrm{~km}$ de algum Posto, portanto, perto do atendimento médico.

Em julho de 1985, abrimos um novo Posto Médico de atendimento no povoado de Algodão-D, localizado ao sul de Itamari (Ver Mapa), dentro da Mata Atlântica, onde pudemos detectar 8 pacientes com a forma mucosa - todos residindo em um raio de $12 \mathrm{~km}$ do Posto.

De tais dados pudemos supor que, ou as pessoas desta região não vêm de muito longe, como pensávamos a principio, ${ }^{5} \mathrm{em}$ busca de auxilio médico, ou a noticia deste auxílio não está chegando tão eficazmente a eles.

Do total de 108 pacientes de forma mucosa pudemos observar ainda que 91 casos $(84 \%)$ re- sidem na Mata Atlântica ${ }^{4} \mathrm{e}$ apenas 17 (16\%) residem atualmente nas vilas e povoados ou perto destes; coincidência tão marcante entre forma mucosa e florestas faz-nos pensar que o vetor e o rervatório silvestre da Leishmania braziliensis braziliensis encontra-se nas florestas.

\section{REFERÊNCIAS BIBLIOGRÁFICAS}

1. Asmar SR. Sociologia da microrregião cacaueira. Itagrafe 01-115, 1983.

2. Barretto AC, Cuba CAC, Marsden PD, Vexenat JA, De Belder M. Caracteristicas epidemiológicas da leishmaniose tegumentar americana em uma regiào endèmica do Estado da Bahia, Brasil. I - Leishmaniose humana. Boletim da Oficina Sanitária Panamericana 90:41 5-424, 1981.

3. Cuba CAC, Marsden PD, Barretto AC, Roitman I. Identification of human stocks of Leishmania spp isolated from patients with mucocutaneous leishmaniasis in Très Braços, Bahia, Brasil. Transactions of the Royal Society of Tropical Medicine and Hygiene 78:708-709, 1984.

4. MAPA - MINTER - SUDENE/Gov. da Bahia redução $1 / 4$ e adaptação do mapa feito a partir de fotografias aéreas 1:108000 tomadas em 1973/74/75.

5. Marsden PD, Llanos-Cuentas EA, Lago EL, Cuba CAC, Barretto AC. Costa JML. Jones TC. Human mucocutaneous leishmaniasis in Très Braços, Bahia Brazil. An area of Leishmania braziliensis brasiliensis transmission. III Mucosal disease presentation and initial evolution. Revista da Sociedade Brasileira de Medicina Tropical 17:179-186, 1984.

6. Pessoa SB, Pestana BR. Sobre a disseminaçào da leishmaniose tegumentar no Estado de São Paulo. Arquivos de Higiene e Saúde Pública, Sāo Paulo 8:35-46, 1940.

7. Sampaio LF. O aparecimento, a expansão e o fim da leishmaniose no Estado de São Paulo. Revista Brasileira de Medicina 8:717-721, 1951.

Eduardo M. Netto

Philip D. Marsden

Jackson M. Costa

Air C. Barreto

Cesar C. Cuba

Núcleo de Medicina Tropical e Nutriçâo,

Universidade de Brasilia 